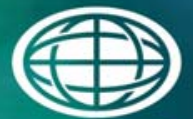

Savannah River

National Laboratory "m

OPERATED BY SAVANNAH RIVER NUCLEAR SOLUTIONS

\title{
Analytical Results from Routine DSSHT and SEHT Monthly Samples
}

T. B. Peters

December 2016

SRNL-STI-2016-00663, Revision 0 


\section{DISCLAIMER}

This work was prepared under an agreement with and funded by the U.S. Government. Neither the U.S. Government or its employees, nor any of its contractors, subcontractors or their employees, makes any express or implied:

1. warranty or assumes any legal liability for the accuracy, completeness, or for the use or results of such use of any information, product, or process disclosed; or

2. representation that such use or results of such use would not infringe privately owned rights; or

3. endorsement or recommendation of any specifically identified commercial product, process, or service.

Any views and opinions of authors expressed in this work do not necessarily state or reflect those of the United States Government, or its contractors, or subcontractors.

\section{Printed in the United States of America \\ Prepared for U.S. Department of Energy}


Keywords: $M C U$

Retention: Permanent

\section{Analytical Results from Routine DSSHT and SEHT Monthly Samples}

T. B. Peters

December 2016

Prepared for the U.S. Department of Energy under contract number DE-AC09-08SR22470. 


\section{REVIEWS AND APPROVALS}

\section{AUTHORS:}

T. B. Peters, Advanced Characterization and Processing

Date

TECHNICAL REVIEW:

C. A. Nash, Advanced Characterization and Processing, Reviewed per E7 2.60

Date

APPROVAL:

B. J. Wiedenman, Manager

Date

Advanced Characterization and Processing

D. E. Dooley, Director

Date

Environmental \& Chemical Process Technology Research Programs

E. A. Brass, Manager

Date

MCU \& Salt/Sludge Engineering 


\section{EXECUTIVE SUMMARY}

Strip Effluent Hold Tank (SEHT) and Decontaminated Salt Solution Hold Tank (DSSHT) samples from several of the "microbatches" of Integrated Salt Disposition Project (ISDP) Salt Batch ("Macrobatch") 8B have been analyzed for ${ }^{238} \mathrm{Pu},{ }^{90} \mathrm{Sr},{ }^{137} \mathrm{Cs}$, cations (Inductively Coupled Plasma Emission Spectroscopy - ICPES), and anions (Ion Chromatography Anions - IC-A).

The analytical results from the current microbatch samples are similar to those from previous macrobatch samples. The Cs removal continues to be excellent, with decontamination factors (DF) averaging 22,100 (114\% RSD).

The bulk chemistry of the DSSHT and SEHT samples do not show any signs of unusual behavior, other than lacking the anticipated degree of dilution that is calculated to occur during Modular Caustic-Side Solvent Extraction Unit (MCU) processing. 


\section{TABLE OF CONTENTS}

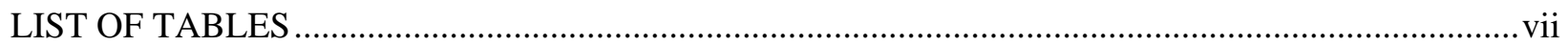

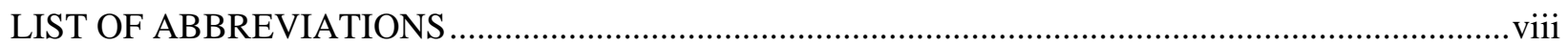

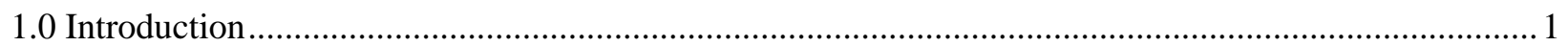

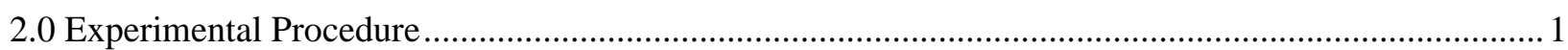

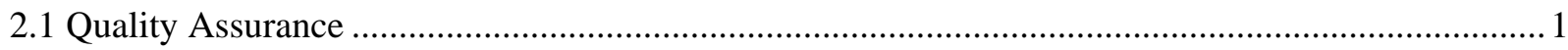

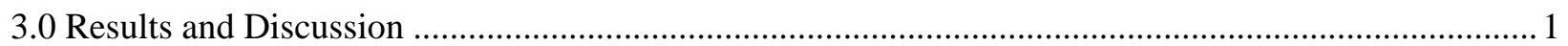

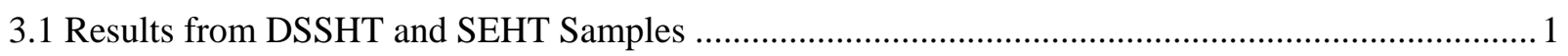

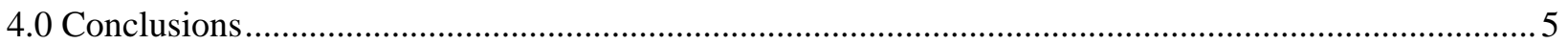

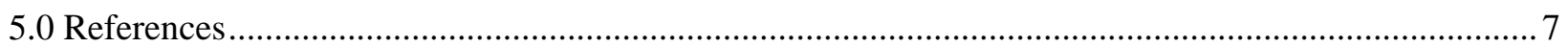




\section{LIST OF TABLES}

Table 1. Radiochemical Results for the DSSHT and SEHT Samples ....................................................

Table 2. Average Cs DF Values from Macrobatch 7B and 8B.........................................................2

Table 3. Average Pu and Sr DF Values from Macrobatches 7B and 8B ..............................................

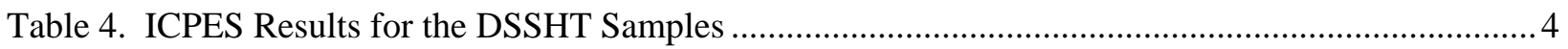

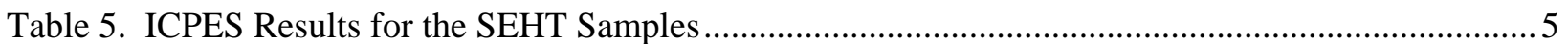




\section{LIST OF ABBREVIATIONS}

$\begin{array}{ll}\text { AD } & \text { Analytical Development } \\ \text { ARP } & \text { Actinide Removal Process } \\ \text { CF } & \text { Concentration Factor } \\ \text { DF } & \text { Decontamination Factor } \\ \text { DSS } & \text { Decontaminated Salt Solution } \\ \text { DSSHT } & \text { Decontaminated Salt Solution Hold Tank } \\ \text { IC-A } & \text { Ion chromatography - anions } \\ \text { ICPES } & \text { Inductively-coupled plasma emission spectroscopy } \\ \text { ISDP } & \text { Interim Salt Disposition Project } \\ \text { MCU } & \text { Modular Caustic-Side Solvent Extraction Unit } \\ \text { MST } & \text { Monosodium titanate } \\ \text { NGS } & \text { Next Generation Solvent } \\ \text { RSD } & \text { Relative standard deviation } \\ \text { SE } & \text { Strip Effluent } \\ \text { SEHT } & \text { Strip Effluent Hold Tank } \\ \text { SRNL } & \text { Savannah River National Laboratory } \\ \text { SSFT } & \text { Salt Solution Feed Tank } \\ \text { TTQAP } & \text { Task Technical and Quality Assurance Plan }\end{array}$




\subsection{Introduction}

During operation of the ISDP, quantities of salt waste are processed through Actinide Removal Process (ARP) and MCU in batches of 3,800 gallons. Until recently, Monosodium Titanate (MST) was used in ARP to adsorb actinides and strontium from the salt waste, then the waste slurry is filtered prior to sending the clarified salt solution to MCU. The MCU uses solvent extraction technology to extract cesium from salt waste and concentrate cesium in an acidic aqueous stream (Strip Effluent - SE), leaving a decontaminated caustic salt aqueous stream (Decontaminated Salt Solution - DSS). Sampling occurs in the DSSHT and SEHT in the MCU process. The MCU sample plan requires that batches be sampled and analyzed on a quarterly frequency for plutonium and strontium content by the Savannah River National Laboratory (SRNL) to determine MST effectiveness. ${ }^{i}$ A Task Technical and Quality Assurance Plan (TTQAP) were prepared to cover routine analyses. ${ }^{\text {ii }}$ The cesium measurement is used to monitor cesium removal effectiveness while the ICPES and IC-A are used to monitor inorganic carryover.

A previous report provided the results of several sets of sample results from Macrobatch 8B operations. ${ }^{\text {iii }}$ Since that report, SRNL analyzed a series of samples from May 2016 through July 2016 (end of Salt Batch 8 processing). The sample results described in this report are from Macrobatch 8B.

\subsection{Experimental Procedure}

The samples were contained in 10-mL P-nut vials. SEHT samples were delivered in doorstops for shielding purposes, while the DSSHT samples were delivered in "thief" holders. Samples of the same type were each composited into a single bottle. The SEHT samples were analyzed for ${ }^{137} \mathrm{Cs},{ }^{238} \mathrm{Pu}$, ${ }^{239 / 40} \mathrm{Pu}$ and ${ }^{90} \mathrm{Sr}$ content, as well as for cation content (ICPES). The DSSHT samples were also analyzed for anion content (IC-A). The DSSHT samples were sent for analysis without dilution or filtration. SEHT samples were sent for analysis with dilution using deionized water only when necessary, but without filtration.

\subsection{Quality Assurance}

Requirements for performing reviews of technical reports and the extent of review are established in manual E7 2.60. For SRNL documents, the extent and type of review using the SRNL Technical Report Design Checklist is outlined in WSRC-IM-2002-00011, Rev. 2. ${ }^{\text {iv }}$ Records for this work are contained in an electronic notebook ELN-A4571-00084-26.

\subsection{Results and Discussion}

\subsection{Results from DSSHT and SEHT Samples}

The ${ }^{137} \mathrm{Cs}$, ${ }^{90} \mathrm{Sr}$, and ${ }^{238} \mathrm{Pu}$ results from the DSSHT and SEHT radiochemical analyses are listed in Table 1. These samples were roughly monthly samples. Values in parentheses are the 1 sigma analytical uncertainties as provided by Analytical Development (AD). The source material 
(Tank 49H) entries were derived from customer blend documents for Salt Batch 8B, and are used for comparison.

Table 1. Radiochemical Results for the DSSHT and SEHT Samples

\begin{tabular}{|c|c|c|c|c|}
\hline Sample ID & Sample Date & ${ }^{238} \mathbf{P u}(\mathbf{d p m} / \mathbf{m L})$ & $\left.{ }^{\mathbf{9 0}} \mathrm{Sr} \mathbf{( d p m} / \mathbf{m L}\right)$ & ${ }^{\mathbf{1 3 7}} \mathbf{C s}(\mathbf{d p m} / \mathbf{m L})$ \\
\hline \multicolumn{5}{|c|}{ DSSHT Samples } \\
\hline MCU-16-704/705/706 & $5 / 23 / 2016$ & $7.12 \mathrm{E}+04(9.9 \%)$ & $6.40 \mathrm{E}+05(26 \%)$ & $7.32 \mathrm{E}+04(5.0 \%)$ \\
\hline MCU-16-931/932/933 & $6 / 30 / 2016$ & $9.25 \mathrm{E}+04(6.9 \%)$ & $5.29 \mathrm{E}+05(24 \%)$ & $6.45 \mathrm{E}+04(5.0 \%)$ \\
\hline MCU-16-988/989/990 & $7 / 13 / 2016$ & $7.32 \mathrm{E}+04(8.9 \%)$ & $8.01 \mathrm{E}+05(26 \%)$ & $5.71 \mathrm{E}+03(5.0 \%)$ \\
\hline \multicolumn{5}{|c|}{ SEHT Samples } \\
\hline MCU-16-707/708/709 & $5 / 23 / 2016$ & $8.07 \mathrm{E}+01(34 \%)$ & $<2.70 \mathrm{E}+04$ & $6.64 \mathrm{E}+09(5.0 \%)$ \\
\hline MCU-16-928/929/930 & $6 / 30 / 2016$ & $4.28 \mathrm{E}+01(32 \%)$ & $6.11 \mathrm{E}+03(24 \%)$ & $6.38 \mathrm{E}+09(5.0 \%)$ \\
\hline MCU-16-997/998/999 & $7 / 13 / 2016$ & $<2.51 \mathrm{E}+02$ & $6.43 \mathrm{E}+03(29 \%)$ & $6.31 \mathrm{E}+09(5.0 \%)$ \\
\hline \multicolumn{6}{|c|}{ Source Material (8B) } & $1.15 \mathrm{E}+05$ & $1.03 \mathrm{E}+06$ & $4.35 \mathrm{E}+08$ \\
\hline
\end{tabular}

Previously, ARP stopped striking with MST. This explains the small decrease in ${ }^{238} \mathrm{Pu}$ and ${ }^{90} \mathrm{Sr}$ results for the DSSHT samples. The small decline indicates some small amount of removal from residual fines and/or dilution effects. The lack of MST use does not affect the ${ }^{137} \mathrm{Cs}$ removal and the values in the DSSHT are typical. The ${ }^{137} \mathrm{Cs}$ values in the SEHT are increasing towards the theoretical maximum of $\sim 7.1 \mathrm{E}+09 \mathrm{dpm} / \mathrm{mL}$.

For Cs, the relevant comparison is between the Macrobatch 7B operations with the Next Generation Solvent (NGS) (Table 2). ${ }^{\text {iii }}$ The values in parentheses are the \% relative standard deviation.

Table 2. Average Cs DF Values from Macrobatch 7B and 8B

\begin{tabular}{|c|c|c|}
\hline Isotope & Average 7B & Average 8B \\
\hline${ }^{137} \mathrm{Cs}$ & $20900(111 \%)$ & $22100(114 \%)$ \\
\hline
\end{tabular}

The large standard deviations associated with the cesium removal are due to the large fluctuations in the DSSHT sample values. Proper cesium removal behavior at steady state operations can routinely achieve DF in the 30,000+ range. On the other hand, startup on untreated Salt Solution Feed Tank (SSFT) feed versus starting the MCU process with the DSSHT material can cause an increase in the DSSHT ${ }^{137}$ Cs values.

Historically, the concentration factor $\left({ }^{137} \mathrm{Cs}\right.$ in the strip effluent divided by the ${ }^{137} \mathrm{Cs}$ in the Tank $49 \mathrm{H}$ feed - CF) of MCU has been in the 12-14 range. For these samples of Salt Batch 8B, the 
average CF is 14.8 (2.72\% RSD), which is slightly higher than the previous reported CF value

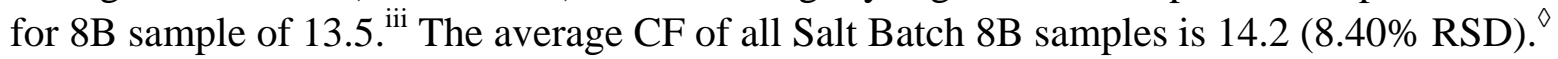

While the use of the NGS blend does not affect the performance of the $\mathrm{Pu}$ and Sr removal, sample analysis from the DSSHT provides an indication of the system-wide dilution effects. Table 3 lists the average DF values for ${ }^{238} \mathrm{Pu}$ and ${ }^{90} \mathrm{Sr}$ for Macrobatch 7B and Macrobatch 8B. ${ }^{\Pi}$ Only one sample (December 2015) in Macrobatch 8B was pulled during the period when MST was in use ("w/MST"). Also provided are the DF values for samples pulled after the discontinuation of the MST strike ("no MST"). The purpose in comparing the three macrobatches is to establish that the average decontamination of these three isotopes is approximately the same. Given the differences in the feed and in operating conditions, variations in the DF values are expected. The high percent relative standard deviation (\%RSD) also makes it problematic to make direct comparisons. The differences between the Macrobatches are not unusual.

Table 3. Average Pu and Sr DF Values from Macrobatches 7B and 8B

\begin{tabular}{|c|c|c|c|}
\hline Isotope & $\begin{array}{c}\text { Average } \\
\text { Macrobatch 7B } \\
\text { DF }\end{array}$ & $\begin{array}{c}\text { Average } \\
\text { Macrobatch 8B DF } \\
\text { (w/MST) }\end{array}$ & $\begin{array}{c}\text { Average } \\
\text { Macrobatch 8B DF } \\
\text { (no MST) }\end{array}$ \\
\hline${ }^{238} \mathrm{Pu}$ & $32.8(53 \%)$ & 19.1 & $1.33(18 \%)$ \\
\hline${ }^{90} \mathrm{Sr}$ & $80.7(27 \%)$ & 152 & $1.81(20 \%)$ \\
\hline
\end{tabular}

It is interesting to note that for these samples which were pulled after discontinuation of the MST strike, there is still a slight, but consistent removal of Pu and Sr. This is likely due to filtration at 512-S removing $\mathrm{Pu}$ and Sr-containing fines and/or dilution effects on the feed as it passes through the ARP and MCU system.

The meaningful (present in non-trace quantities) ICPES (B, Cr, Na) and IC-A (nitrite, nitrate, sulfate) results for the DSSHT samples are listed in Table 4 and the meaningful ICPES results for the SEHT samples are listed in Table 5. The analytes in the DSSHT are relatively stable over all the samples, with the exceptions of analytes that are potentially subject to solubility swings. The low $\mathrm{Al}$ in several samples indicates potential precipitation, for example.

The material from Tank $21 \mathrm{H}$ undergoes a $\sim 13$ vol \% dilution from ARP and MCU while no MST is in use. ${ }^{\mathrm{vi}}$ Therefore, direct comparisons between the source material and the DSSHT sample results should take this into account. Of the reported analytes in Table 4, B, Cr, Na, nitrite, nitrate, and sulfate are analytes that are only subject to dilution effects in the ARP/MCU system - they are not affected by the solvent extraction, nor are they subject to solubility changes.

\footnotetext{
${ }^{\diamond}$ The average CF of all the Salt Batch 8B samples does not include the January 2016 result which was physically impossible.

${ }^{\Pi}$ Recall that DF is defined as the feed value divided by the DSSHT sample value.
} 
These analytes are shaded in Table 4. In Table 4, the "\% decline from feed concentration" row is the average of six analytes percentage decline compared to the value of their concentration in Salt Batch 8B feed. For example, for the MCU-16-931/2/3 sample, the six analytes are an average of $102.2 \%$ of their respective concentrations in the Salt Batch 8B feed.

Table 4. ICPES Results for the DSSHT Samples

\begin{tabular}{|c|c|c|c|c|}
\hline \multirow{2}{*}{ Analyte } & \multicolumn{4}{|c|}{ MCU-16-xxx Sample ID (mg/L) } \\
\hline & Feed 8B ${ }^{\text {v,vii }}$ & $16-704 / 5 / 6$ & $16-931 / 2 / 3$ & $16-988 / 89 / 90$ \\
\hline $\mathrm{Al}$ & 5260 & 4730 & 4300 & 4590 \\
\hline $\mathrm{B}$ & 64.0 & 69.8 & 63.6 & 78.3 \\
\hline $\mathrm{Cr}$ & 69.0 & 70.1 & 64.4 & 70 \\
\hline $\mathrm{K}$ & 605 & 525 & 480 & 529 \\
\hline $\mathrm{Na}$ & 145000 & 150000 & 133000 & 141000 \\
\hline $\mathrm{P}^{\Upsilon}$ & 175 & 218 & 211 & 241 \\
\hline$S^{\Upsilon}$ & 2570 & 2580 & 2360 & 2560 \\
\hline $\mathrm{Si}$ & 57.3 & 59.9 & 108 & 166 \\
\hline $\mathrm{Ti}$ & $<0.93$ & $<8.96$ & $<4.65$ & $<8.96$ \\
\hline $\mathrm{Zn}$ & 4.65 & 5.74 & 6.26 & $<5.92$ \\
\hline$F$ & 97.3 & $<100$ & $<10$ & $<100$ \\
\hline Formate & 468 & 129 & 322 & 319 \\
\hline $\mathrm{Cl}$ & 385 & 405 & 398 & 405 \\
\hline Nitrite & 37100 & 37000 & 34700 & 35400 \\
\hline Nitrate & 124000 & 104000 & 101000 & 101000 \\
\hline Phosphate & 537 & 500 & 454 & 442 \\
\hline Sulfate & 5530 & 6400 & 5460 & 5440 \\
\hline oxalate & 203 & 161 & 210 & 224 \\
\hline $\begin{array}{l}\text { \% decline from } \\
\text { feed concentration }\end{array}$ & NA & $-2.24 \%$ & $6.98 \%$ & $0.620 \%$ \\
\hline
\end{tabular}

The analytical uncertainty for the ICPES and IC-A analyses is $10 \%$.

The measured \% decline in concentrations is always less than what is predicted (13\%). This trend has been noted in the previous 8B samples. In some cases, the average decline is negative, indicating that on average the analytes are more slightly more concentrated than what is in the feed. Since the discontinuation of the use of MST, the \% decline from feed has decreased. For Salt Batch 7B samples, the average \% decline was 16.7\%. For the single Salt Batch 8B sample that was taken during MST use, the \% decline was 8.8\%. Samples taken after the discontinuation of MST then showed a decrease in the \% decline. To put it simply, when

\footnotetext{
${ }^{\Upsilon}$ While the $\mathrm{P}$ and $\mathrm{S}$ results can nominally be used to calculate the phosphate and sulfate, respectively, there is a greater uncertainty in doing so, compared to using the IC-Anions method result.
} 
comparing the results of the DSSHT samples to the feed values, SRNL does not note the anticipated level of dilution from processing.

A recent document examined two SSFT samples. ${ }^{\text {vii }}$ It was found that on average, the SSFT samples showed a $<2 \%$ decline in concentrations compared to the feed. This indicates that the Salt Batch 8B feed values, which are calculated values, are likely close to the actual composition of Tank $49 \mathrm{H}$ material (there should be little change in concentration between the feed and the SSFT).

If the feed values are correct, then it may be possible that concentration of the feed is occurring during processing at MCU, through evaporation of water.

For the ICPES data from the SEHT samples, there are few analytes (boron, potassium and sodium) that consistently appear in concentrations above the detection limit. Boron should consistently be at $108 \mathrm{mg} / \mathrm{L}$ since the SEHT is a solution of $0.01 \mathrm{M}$ boric acid. While the boron values indicate the boric acid concentrations are low, they are within acceptable procurement specifications. Sodium and potassium concentrations are consistent with previous data.

Table 5. ICPES Results for the SEHT Samples

\begin{tabular}{|c|c|c|c|}
\hline \multirow{2}{*}{ Analyte } & \multicolumn{3}{|c|}{ MCU-16-xxx Sample ID (mg/L) } \\
\cline { 2 - 4 } & $16-707 / 8 / 9$ & $16-928 / 9 / 30$ & $16-997 / 8 / 9$ \\
\hline $\mathrm{B}$ & 102 & 93.8 & 94.1 \\
\hline $\mathrm{K}$ & 18.7 & 19.1 & 19.6 \\
\hline $\mathrm{Na}$ & 46.4 & 33.9 & 50.7 \\
\hline
\end{tabular}

The analytical uncertainty for the ICPES analysis is $10 \%$.

\subsection{Conclusions}

SEHT and DSSHT samples from several of the "microbatches" of ISDP Salt Batch (“Macrobatch") 8B have been analyzed for ${ }^{238} \mathrm{Pu},{ }^{90} \mathrm{Sr},{ }^{137} \mathrm{Cs}$, cations (ICPES), and anions (IC-A).

The analytical results from the current microbatch samples are similar to those from previous macrobatch samples. Even with no MST strike being performed there exists some small Pu and Sr removal, likely from filtration of fines containing these elements.

In MCU the Cs removal continues to be excellent, with decontamination factors averaging 22,100 (114\% RSD). 
The bulk chemistry of the DSSHT and SEHT samples do not show any signs of unusual behavior, other than lacking the anticipated degree of dilution that is calculated to occur during MCU processing. 


\subsection{References}

${ }^{\mathrm{i}}$ M. W. Geeting, “Interim Salt Disposition Project (ISDP) Sample Plan”, U-ESR-H-00068, Revision 5, April 28, 2009.

${ }^{i i}$ T. B. Peters, A. L. Washington II, F. F. Fondeur, “Task Technical and Quality Assurance Plan for Routine Samples in Support of ARP and MCU”, SRNL-RP-2013-00536, rev. 1, May 2014.

iii T. B. Peters, "Analytical Results from Routine DSSHT and SEHT Monthly Samples”, SRNLSTI-2016-00384, August 2016.

iv Savannah River National Laboratory, “Technical Report Design Check Guidelines”, WSRCIM-2002-00011, Rev. 2.

${ }^{\vee}$ D. L. McWhorter, "Blend Evaluation for Tank 49 Feed for ISDP Salt Batch 8-B August 2015", X-ESR-H-00769, August 4, 2015.

${ }^{v i}$ A. G. Garrison, "Evaluation of Interim Salt Disposition Project (ISDP) Macrobatch Dilution Bases Experienced at Actinide Removal Process and Modular Caustic Solvent Extraction Unit (ARP/MCU)”, X-ESR-H-00724, rev. 1, May 28, 2015.

${ }^{\text {vii }}$ T. B. Peters, A. L. Washington II, "Sample Results from the Interim Salt Disposition Program Macrobatch 8 Tank 21H Qualification Samples” SRNL-STI-2014-00561, rev. 1, January 2015.

viii T. B. Peters, “Analytical Results from Salt Solution Feed Tank (SSFT) Samples HTF-16-6 and HTF-16-40”, SRNL-STI-2016-00407, September 2016. 


\section{Distribution:}

T. B. Brown, 773-A

M. E. Cercy, 773-42A

D. A. Crowley, 773-43A

D. E. Dooley, 773-A

A. P. Fellinger. 773-42A

S. D. Fink, 773-A

C. C. Herman, 773-A

D. T. Hobbs, 773-A

E. N. Hoffman, 999-W

J. E. Hyatt, 773-A

K. M. Kostelnik, 773-42A

B. B. Looney, 773-42A

D. A. McGuire, 773-42A

T. O. Oliver, 773-42A

F. M. Pennebaker, 773-42A

G. N. Smoland, 773-42A

B. J. Wiedenman, 773-42A

W. R. Wilmarth, 773-A

P. R. Jackson, DOE-SR, 703-46A

J. A. Crenshaw, 703-46A

Records Administration (EDWS)

E. A. Brass, 241-121H

C. K. Chiu, 704-30S

E. J. Freed, 704-S

A. G. Garrison, 241-121H

B. A. Gifford, 704-56H

V. Jain, 766-H

R. T. McNew, 766-H

M. A. Rios-Armstrong, 766-H

A. R. Shafer, 766-H

C. M. Santos, 241-152H

P. E. Fogelman, 241-121H

K. M. Marra, 241-120H

T. C. Demeter, 704-25S

A. Samadi-Dezfouli, 707-4E

C. Sudduth, 707-7E

A. W. Wiggins, $241-168 \mathrm{H}$

T. L. Fellinger, 766-H 